\title{
Friction and wear performance of HFCVD nanocrystalline diamond coated silicon nitride ceramics
}

\author{
C.S. Abreu ${ }^{\text {a }}$, M. Amaral ${ }^{\text {b }}$, A.J.S. Fernandes ${ }^{\text {c }}$, F.J. Oliveira ${ }^{\text {b }}$, R.F. Silva ${ }^{\text {b,* }}$, J.R. Gomes ${ }^{\text {d }}$ \\ a Physics Department, ISEP, Portugal \\ ${ }^{\mathrm{b}}$ CICECO, University of Aveiro, Portugal \\ ${ }^{c}$ Physics Department, University of Aveiro, Portugal \\ ${ }^{\mathrm{d}}$ Mech. Eng. Department, CIICS, Univ. of Minho, Portugal
}

Available online 1 December 2005

\begin{abstract}
Silicon nitride $\left(\mathrm{Si}_{3} \mathrm{~N}_{4}\right)$ ceramics were selected as substrates due to their thermal and chemical compatibility to diamond that ensure the adequate $\mathrm{NCD}$ adhesion for mechanical purposes. NCD deposition was performed by hot-filament chemical vapour method (HFCVD) using $\mathrm{Ar} / \mathrm{H}_{2} / \mathrm{CH} 4$ gas mixtures. The tribological assessment of homologous pairs of NCD films was accomplished using reciprocating ball-on-flat tests using NCD coated $\mathrm{Si}_{3} \mathrm{~N}_{4}$ plates and balls. The friction evolution is characterized by an initial running-in regime with a sharp peak up to 0.7 , shortly followed by a steady-state regime identified by very low friction coefficients values $(0.02-0.03)$. The threshold load prior to delamination depends on the starting surface roughness of the substrates and attains a value of $\sim 40 \mathrm{~N}$. In terms of wear performance, the NCD films reveal a mild wear regime $\left(K \sim 10^{-7} \mathrm{~mm}^{3} \mathrm{~N}^{-1} \mathrm{~m}^{-1}\right)$ for self-mated dry sliding conditions.
\end{abstract}

(C) 2005 Elsevier B.V. All rights reserved.

Keywords: Nanocrystalline; Hot-filament CVD; Tribology

\section{Introduction}

Nanocrystalline diamond coatings (NCD) are gaining increasing interest as serious candidate materials for high performance engineering surfaces in mechanical and tribological applications, due to their intrinsic smoothness combined with most of the outstanding properties of natural single-crystal diamond [1]. Highly demanding tribological applications where NCD coatings are already in use or thought of vary from the fluid handling and cutting tools industries to, more recently, micro-electromechanical systems (MEMS) and biomedical applications [2-4].

The wear performance and, more extensively, the friction properties of NCD coatings sliding against metallic or ceramic dissimilar counterpairs have been studied [5,6]. However, to our knowledge, no reports are found in the literature concerning the

\footnotetext{
* Corresponding author. Tel.: +351 234370243; fax: +351 234425300.

E-mail address: rsilva@cv.ua.pt (R.F. Silva).
}

tribological performance of unlubricated homologous pairs of NCD films under high applied stresses.

Silicon nitride $\left(\mathrm{Si}_{3} \mathrm{~N}_{4}\right)$ ceramics constitute a novel and prospective substrate material for the deposition of NCD films due to their chemical compatibility and low thermal mismatch with diamond, which translates as an improved adhesion [7,8]. Being one of the toughest ceramic materials, it possesses an advantageous combination of intrinsic mechanical, thermal and chemical properties, as well as good wear resistance, imperative for demanding tribomechanical applications.

The hot-filament chemical vapour deposition (HFCVD) technique is one of the most common available methods of producing polycrystalline diamond films and, more recently, NCD films. This versatile CVD based deposition technique allows the diamond deposition in a simple and cost-effective way, overcoming some of the limitations of other more sophisticated CVD techniques such as microwave plasma CVD (MPCVD), namely in the ability of coating complex geometries.

Reciprocating ball-on-flat experiments were undertaken to assess the tribological behaviour of NCD homologous pairs. 
Three different surface finishing states were employed on the $\mathrm{Si}_{3} \mathrm{~N}_{4}$ substrates. The applied load threshold at which delamination of the films occurs under tribological stress was determined for all tested conditions. Different characterization techniques were used in order to examine the quality, morphology and topography of the deposited and worn NCD films, respectively, $\mu$-Raman spectroscopy, scanning electron microscopy (SEM) and atomic force microscopy (AFM).

\section{Experimental details}

Details on powder preparation and sintering of $\mathrm{Si}_{3} \mathrm{~N}_{4}$ substrates can be found elsewhere [9]. Square substrates $\left(10 \times 10 \times 3 \mathrm{~mm}^{3}\right)$ were cut from dense ceramics, ground and submitted to three different surface finish conditions: (i) flat lapping with $15 \mu \mathrm{m}$ diamond slurry (FL samples); (ii) hard cloth polishing with $15 \mu \mathrm{m}$ diamond slurry (PP); and (iii) polishing to a mirror-like finish with colloidal silica (P). Commercial silicon nitride balls ( $\varnothing 5 \mathrm{~mm}$, Kema Nord) were also used for diamond deposition, in order to act as counterbodies in the sliding experiments. Silicon nitride substrates
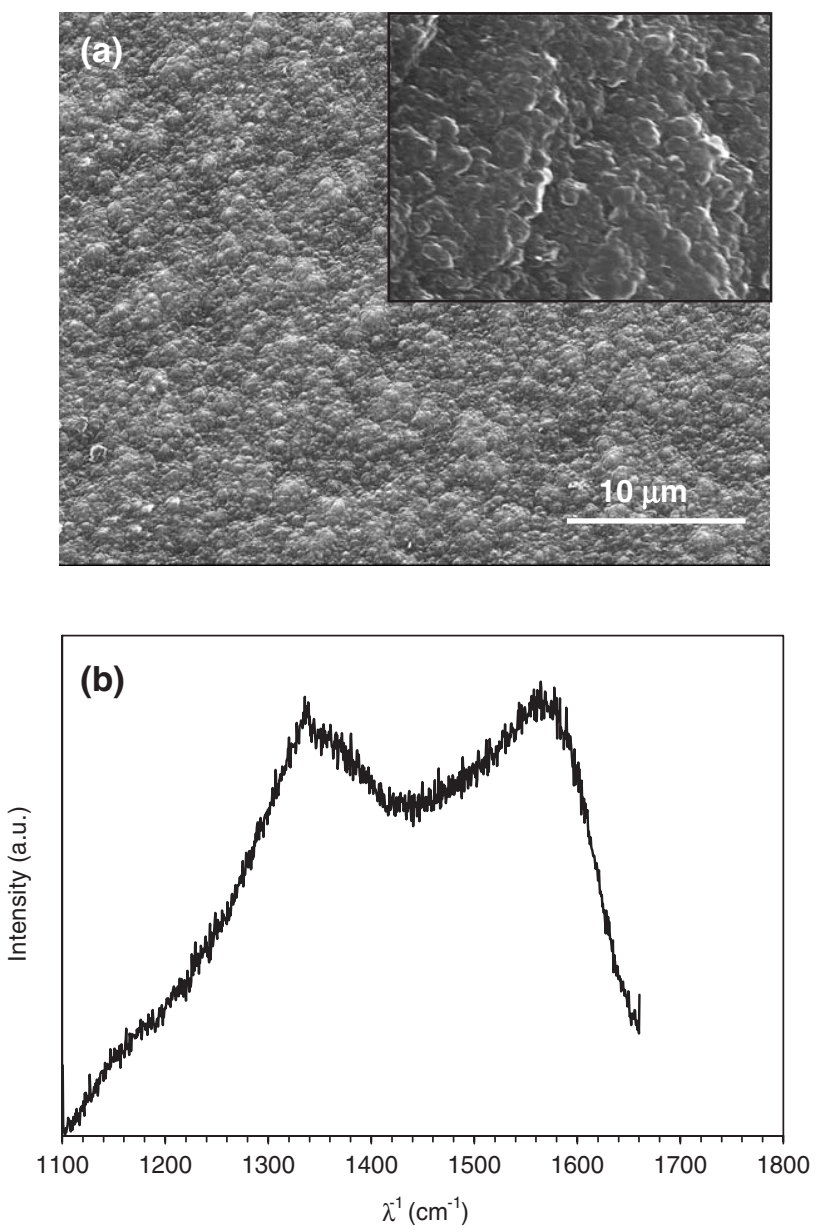

Fig. 1. (a) Morphology of a representative NCD film on a $\mathrm{Si}_{3} \mathrm{~N}_{4}$ ball substrate. The inset shows a detail five times magnified relative to the main micrograph; (b) Raman spectrum of a typical as-deposited NCD film. were then scratched for $1 \mathrm{~h}$ in an ultrasonic suspension with 1 $\mu \mathrm{m}$ diamond powder in $n$-hexane $(1 \mathrm{~g} / 100 \mathrm{ml})$. Nanocrystalline diamond films were grown by the HFCVD technique using an $\mathrm{Ar} / \mathrm{CH}_{4} / \mathrm{H}_{2}$ gas mixture where the $\mathrm{Ar} / \mathrm{H}_{2}$ and $\mathrm{CH}_{4} / \mathrm{H}_{2}$ ratios were fixed at 0.1 and 0.04 , respectively. The other deposition conditions were the following: W filament temperature -2300 ${ }^{\circ} \mathrm{C}$, total gas flow- $50 \mathrm{ml} \cdot \mathrm{min}^{-1}$, total pressure $-50 \mathrm{mbar}$, substrate temperature $-750{ }^{\circ} \mathrm{C}$. The nanodiamond growth rates were, respectively, $1.6 \mu \mathrm{m} \cdot \mathrm{h}^{-1}$ on the plates and $2.2 \mu \mathrm{m} \cdot \mathrm{h}^{-1}$ on the balls.

All the substrates were characterized by AFM (Digital Instruments, IIIa, USA) before and after deposition in order to distinguish their topographic features. The morphology and thickness of the NCD films were assessed using SEM (Hitachi S4100, J). The NCD quality of the as-deposited films was characterized by a $\mu$-Raman spectrometer (Jobin Yvon T64000, F) with the $514.5 \mathrm{~nm}$ line.

The tribological testing of self-mated NCD films was performed on a ball-on-flat reciprocating sliding tribometer (PLINT TE67/R, UK). Tests were conducted in ambient atmosphere $(\sim 50-60 \% \mathrm{RH})$, under unlubricated conditions, with a constant stroke of $6 \mathrm{~mm}$ and frequency of $1 \mathrm{~Hz}$. Sliding distances were chosen to be of $\sim 86 \mathrm{~m}$ (regular tests) and for the lengthier ones $\sim 690 \mathrm{~m}$ (endurance tests), which correspond to $2 \mathrm{~h}$ and $16 \mathrm{~h}$ of in-interrupt sliding, respectively. Normal loads in the range of 10 to $40 \mathrm{~N}$ were applied by means of dead weights and were kept constant for each run. Considering a purely elastic contact of the sphere/plane surface, these conditions represent a mean Hertzian pressure (normal stress) in the range of 4.4-7.1 GPa $[10,11]$.

Following the sliding tests, the worn NCD surfaces were examined by SEM and AFM techniques. The wear coefficient of the balls was assessed by measuring the corresponding wear scar diameter in SEM.

\section{Results and discussion}

\subsection{Morphology of substrates and as-grown NCD films}

The morphology of the as-deposited NCD films on silicon nitride substrates reveals a good uniformity, as shown in Fig. 1a, for a $\sim 25 \mu \mathrm{m}$ thick film grown on a ball. The included inset exhibits the presence of a pattern of smooth round elevations on the top of which the nanosized diamond grains are perceptible. Fig. $1 \mathrm{~b}$ depicts a representative $\mu$-Raman spectrum of an as-deposited NCD film, containing the diamond characteristic peak at $\sim 1332 \mathrm{~cm}^{-1}$ and the features usually assigned to transpolyacetylene (at 1140 and $1480 \mathrm{~cm}^{-1}$ ), typical of NCD films $[12,13]$. The D and G bands (at 1350 $\mathrm{cm}^{-1}$ and $1580 \mathrm{~cm}^{-1}$, respectively) associated with the $\mathrm{sp}^{2}$ coordinated material are also present.

AFM scans of the $\mathrm{Si}_{3} \mathrm{~N}_{4}$ substrates with the distinct surface finishing conditions analyzed in the present study, along-side with the corresponding deposited NCD films, are presented in Fig. 2. Each 3D plot is accompanied by its respective surface roughness value, $R_{\mathrm{q}}$ (rms). The different uncoated substrate surface finishing quality is clearly evidenced: for the FL 

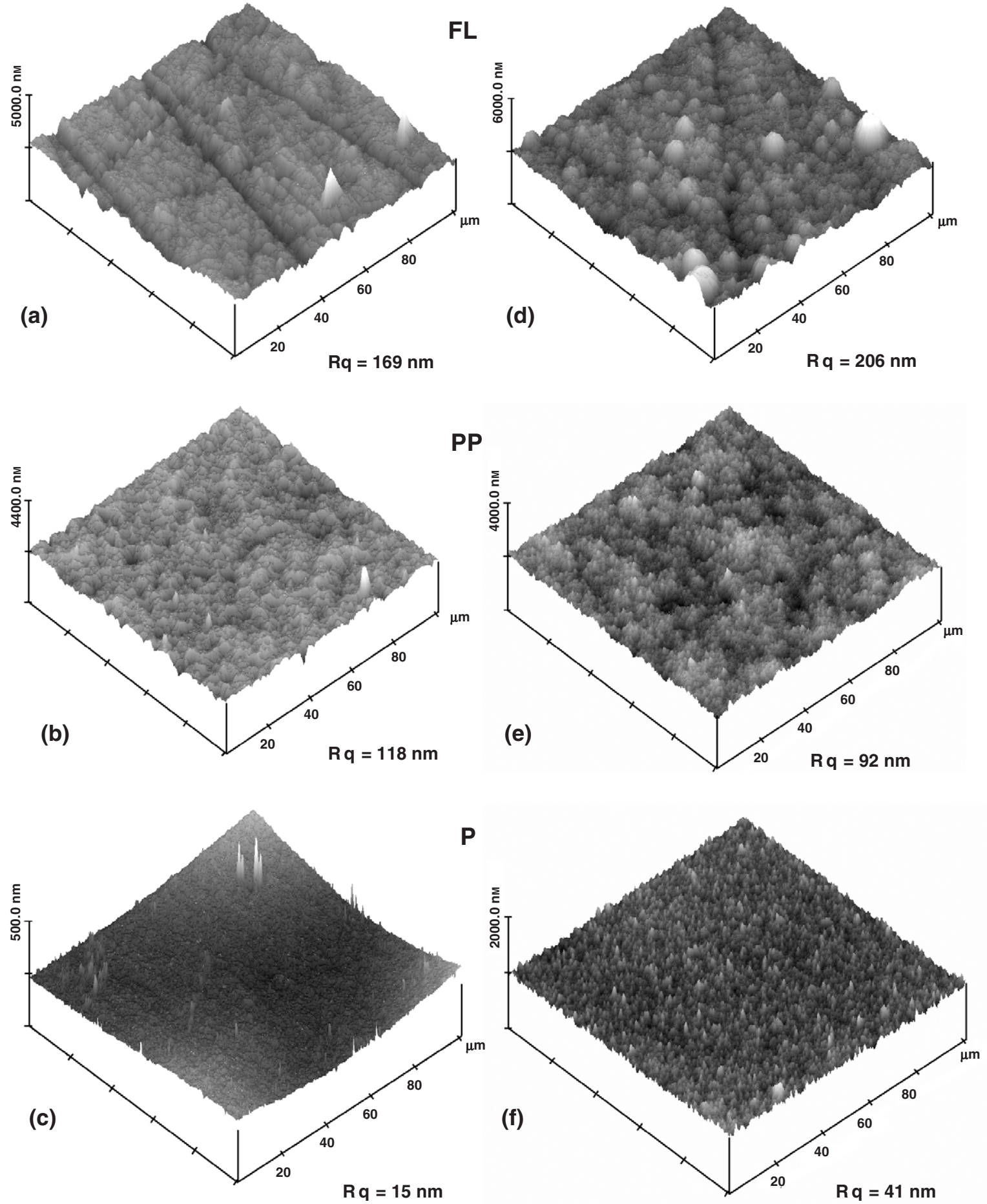

Fig. 2. 3D AFM images of uncoated (left column) and NCD coated (right column) substrates. FL—flat lapped substrate; PP—pre-polished; P—polished.

sample, deep grooves are visible as a result of the roughing operation; for the PP sample, a somewhat irregular surface topography is still patent, however without the presence of grooves; finally, for the $\mathrm{P}$ sample, a high smoothness was achieved. The above described surface distinct conditions are corroborated by their relative $R_{\mathrm{q}}$ values, in the range of $169 \mathrm{~nm}$ for the roughest and of $15 \mathrm{~nm}$ for the smoothest one. After coating, the roughness rank is kept. However, particular phenomena must be taken into account. In fact, for the deposition time used, the film tends to magnify the roughness for rougher starting surfaces, such as in the case of FL sample (Fig. 2a,d). As it can be seen, the NCD film growth follows the grooves of this sample, while prominent conglomerates formed in the vicinity of local asperities, resulting on increased $R_{\mathrm{q}}$ up 
to $206 \mathrm{~nm}$. On the other hand, since the PP sample presents lower starting roughness, the magnifying effect does not take place, a smoothing occurs instead (Fig. 2b,e). For this sample, the NCD smooth deposit actually improves the surface finish, whose initial roughness was not enough to promote the above described magnifying effect. The intrinsic smoothness of the NCD deposits is put in evidence for the case of the P sample, whose starting $R_{\mathrm{q}}$ roughness of $15 \mathrm{~nm}$ augmented to only 41 $\mathrm{nm}$ for a $\sim 20 \mu \mathrm{m}$ thick film. Concerning the NCD coated ball, a nominal roughness of $87 \mathrm{~nm}$ was obtained.

\subsection{Morphology of worn NCD films and tribological behaviour}

As can be seen from the low magnification SEM micrograph of the FL wear track (Fig. 3a), material loss by polishing takes place under an applied load of $20 \mathrm{~N}$ for shorter runs $(\sim 86$ $\mathrm{m})$, without completely masking the deep scratches inherent to this surface finish condition. In the PP wear track, a similar morphology of the worn surface indicates identical phenomena, although a more evenly distribution of polished sites can be observed due to the lower initial roughness associated to this surface finish condition.

At high magnification (Fig. 3c), depressions can be observed alongside with plateaus formed by a self-polishing (micro-abrasion) mechanism, which lead to the truncating of NCD conglomerates and subsequent flattening. The depressions between the plateaus correspond to undamaged NCD regions.

Also noticeable (Fig. 3d) is the crack pattern in lumps of material localized at the edge of the wear tracks, originated from the NCD wear debris smeared by the contact pressure and sliding interaction.

Representative friction evolution curves for each surface finishing condition are depicted in the plots of Fig. $4 a-c$. Regardless the analyzed sample, each friction coefficient $(\mu)$ curve is characterized by an intense narrow initial peak, originated from the mechanical interlocking of the film asperities. Following this main feature, a relatively short transition stage sets-in associated to the flattening of asperities, until the accommodation of the antagonist surfaces is reached. Finally, due to widespread polishing, the friction coefficient levels off, reaching extremely low values in the range of $0.02-$ 0.03. The friction behaviour of FL (Fig. 4a) and PP (Fig. 4b) samples is similar but the initial peak of the FL sample reaches a higher intensity due to its rougher surface.

On the contrary, the curve corresponding to the very smooth $\mathrm{P}$ sample reveals an enlarged friction peak (Fig. 4c) resulting from premature film detachment. In fact, the threshold load for this tribosystem is below $10 \mathrm{~N}$, much lower than the more resistant FL $(40 \mathrm{~N})$ and PP ones $(20 \mathrm{~N})$, denoting poor adhesion. In the $\mathrm{P}$ system, the self-polishing transition regime is absent. Nonetheless, very small values for the friction coefficient are observed after the occurrence of delamination as
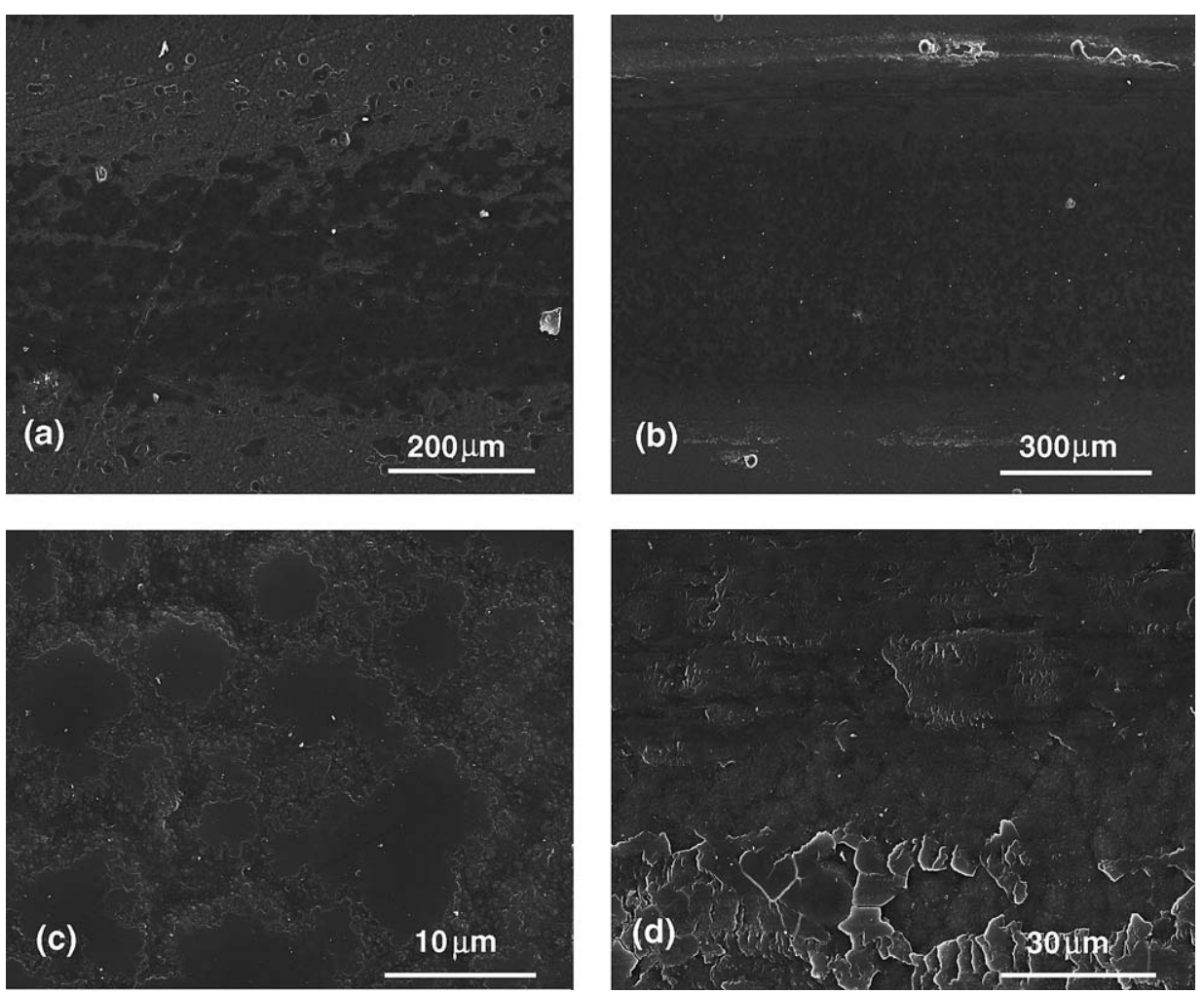

Fig. 3. Aspect of the wear tracks for samples (a) FL and (b) PP under an applied load of $20 \mathrm{~N}$ and a sliding distance of $86 \mathrm{~m}$; (c) detail of polished plateaus, originated from truncated NCD conglomerates; (d) lumps of cracked material at the edge of the wear track. 
(a)

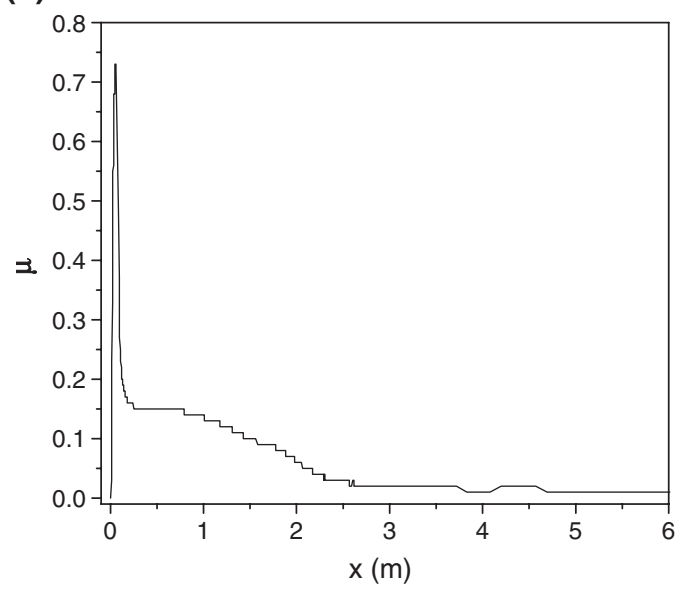

(b)

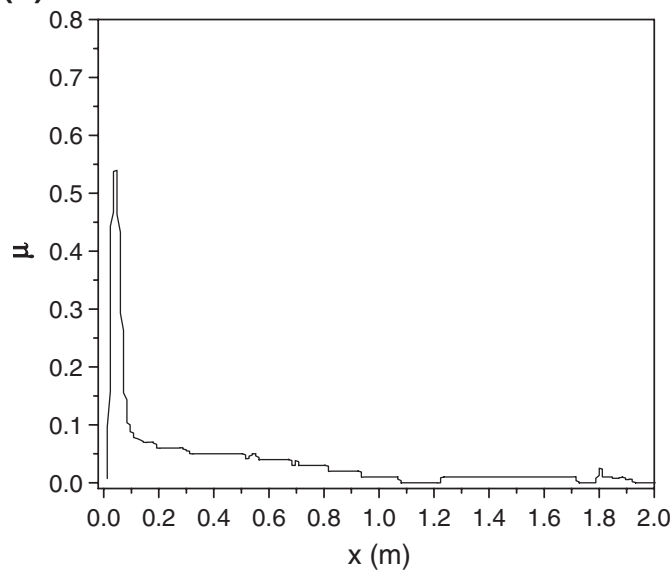

(c)

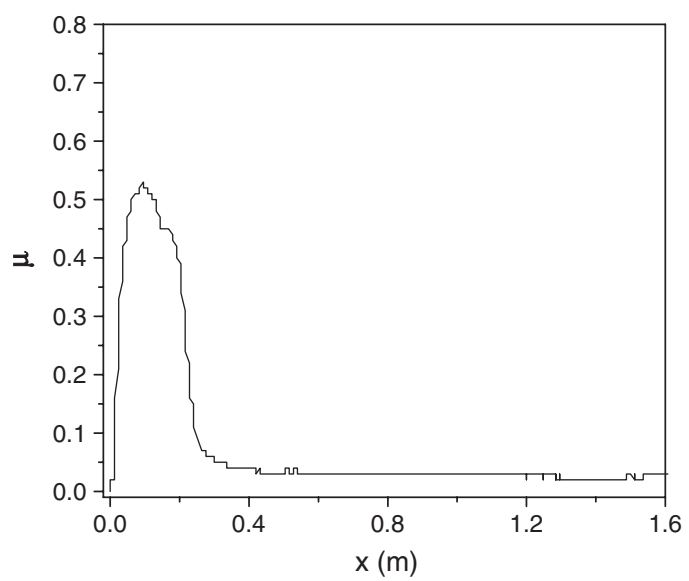

(d)

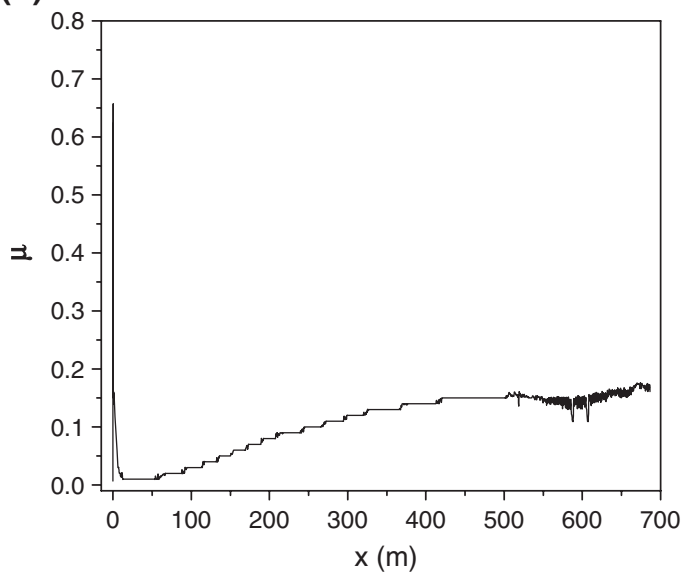

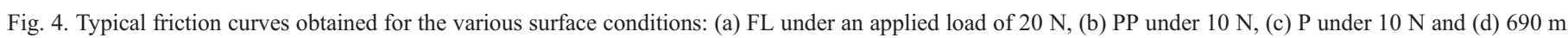
endurance test under $10 \mathrm{~N}$ for a PP sample.

a consequence of the tribological interaction between a smooth NCD film still present in the ball, sliding against a softer exposed $\mathrm{Si}_{3} \mathrm{~N}_{4}$ flat substrate.

For the endurance tests (Fig. 4d), the friction coefficient gradually increases with the sliding distance after remaining at its minimum for distances in the range of the regular tests. This relates to a progressive surface degradation effect that is documented in Fig. 5 for the NCD coated balls, in which cracking is discernible and a chipping wear mechanism is revealed.

The general trend for the NCD friction behaviour is also characteristic of self-mated sliding systems of microcrystalline diamond coated $\mathrm{Si}_{3} \mathrm{~N}_{4}$ ceramics [8]. However, a higher friction peak is obtained for $\operatorname{NCD}(\mu \sim 0.7)$ than for diamond $(\mu \sim 0.25)$ for the same applied load $(20 \mathrm{~N})$. A possible explanation is related to the higher energy required for the truncating of NCD conglomerates when compared to the easier cleavage of micropyramidal sharp crystals, the reported main wear mechanism of diamond.

The reported threshold load prior to delamination for the $\mathrm{Si}_{3} \mathrm{~N}_{4}$ microcrystalline diamond coated tribosystem is $80 \mathrm{~N}$, for a coating thickness close to that of the present work [8]. This value is twice the highest one obtained in the present work for the FL specimen, what denotes lower adhesion levels compared to the microcrystalline deposits. However, the same threshold of $40 \mathrm{~N}$ is found for self-mated tribosystems of NCD grown by MPCVD [14]. The wear performance of self-mated NCD films, in terms of the wear coefficient values for the ball specimens are in the order of $10^{-7} \mathrm{~mm}^{3} \mathrm{~N}^{-1} \mathrm{~m}^{-1}$. These values point out to a mild wear regime. It is noteworthy that a very mild wear $\left(5 \times 10^{-8} \mathrm{~mm}^{3} \mathrm{~N}^{-1} \mathrm{~m}^{-1}\right)$ was measured for the endurance tests, which represent a more accurate assessment of this tribological parameter than the shorter ones. These results are similar to those obtained for self-mated microcrystalline diamond films and NCD grown by MPCVD on the same substrate material $[8,14]$.

\section{Conclusions}

NCD films were grown by HFCVD on $\mathrm{Si}_{3} \mathrm{~N}_{4}$ ceramic substrates presenting surface roughness of $15 \mathrm{~nm}$ to $169 \mathrm{~nm}$. NCD matches the starting surface during growth, mimicking its topography. 

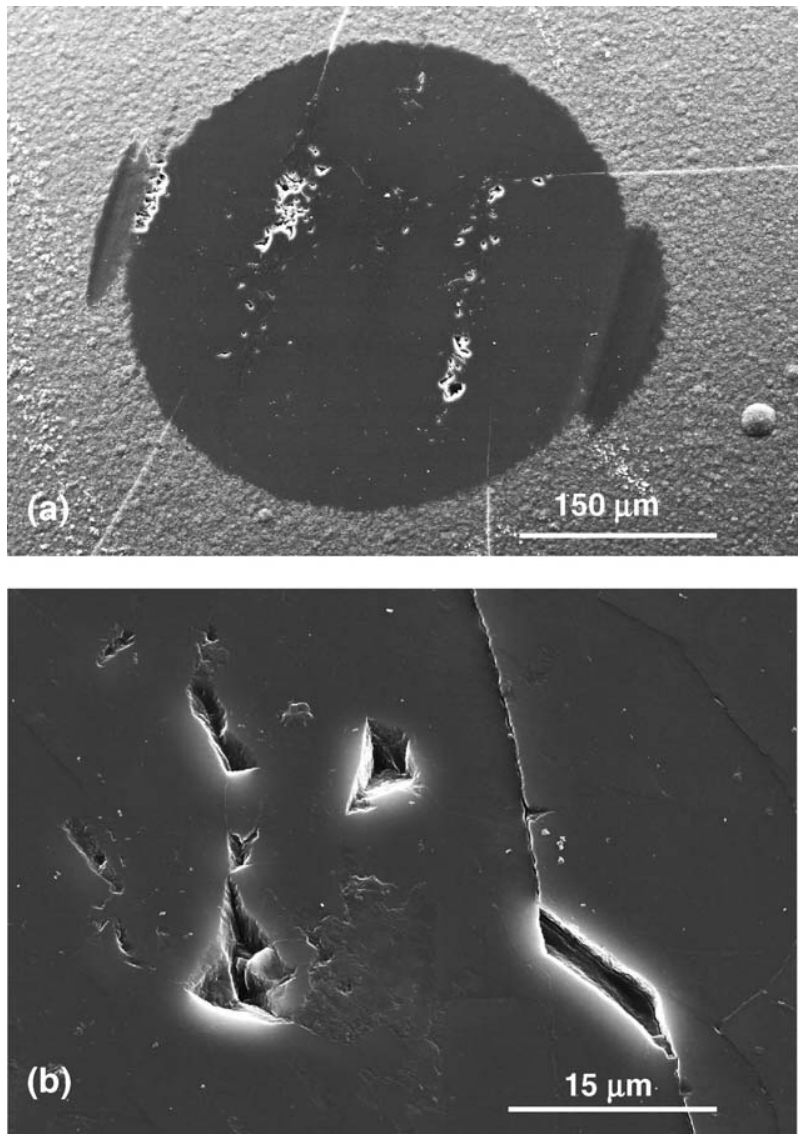

Fig. 5. SEM micrographs taken from a ball specimen, depicting the surface degradation after the endurance tests at different magnifications. Crack features and the chipping wear mechanism are clearly evidenced.

The friction behaviour of the NCD self-mated system is affected by the surface roughness, resulting in intense and ephemeral friction coefficient peaks up to 0.7. After an accommodation period also dependent on the surface roughness, very low $\mu$ values of $0.02-0.03$ are reached for dry sliding conditions. Self-polishing (micro-abrasion) is the predominant wear mechanism of the NCD films resulting in ultra-smooth surfaces. The lengthier tests indicate an increase of $\mu$ up to 0.15 due to some chipping of the worn NCD film on the ball.

The threshold load prior to delamination attained a value of $40 \mathrm{~N}$, which denotes a good adhesion level. Wear coefficient values for the ball specimens are of the order of $\sim 10^{-7} \mathrm{~mm}^{3}$ $\mathrm{N}^{-1} \mathrm{~m}^{-1}$, for the shorter tests, while the endurance tests result in very mild wear regimes $\left(10^{-8} \mathrm{~mm}^{3} \mathrm{~N}^{-1} \mathrm{~m}^{-1}\right)$.

\section{Acknowledgements}

This work was supported by project NANODIAM (FCTPOCTI/CTM/59449/2004).

\section{References}

[1] A. Erdemir, G.R. Fenske, A.R. Krauss, D.M. Gruen, T. McCauley, R.T. Csencsits, Surf. Coat. Technol. 120-121 (1999) 565.

[2] A. Olszyna, J. Smolik, Thin Solid Films 459 (2004) 224.

[3] A.R. Krauss, O. Auciello, D.M. Gruen, A. Jayatissa, A. Sumant, J. Tucek, D. Mancini, N. Moldovan, A. Erdemir, D. Ersoy, M.N. Gardos, H.G. Busmann, E.M. Meyer, M.Q. Ding, Diamond Relat. Mater. 10 (2001) 1952.

[4] J.E. Gerbi, M. Sardela, J.A. Carlisle, Thin Solid Films 473 (2005) 41.

[5] P. Hollman, O. Wanstrand, S. Hogmark, Diamond Relat. Mater. 7 (1998) 1471.

[6] C. Zuiker, A.R. Krauss, D.M. Gruen, X. Pan, J.C. Li, R. Csencsits, A. Erdemir, C. Bindal, G. Fenske, Thin Solid Films 270 (1995) 154.

[7] M. Belmonte, A.J.S. Fernandes, F.M. Costa, F.J. Oliveira, R.F. Silva, Diamond Relat. Mater. 12 (2003) 733.

[8] C.S. Abreu, F.J. Oliveira, M. Belmonte, A.J.S. Fernandes, R.F. Silva, J.R. Gomes, Wear 259 (2005) 771.

[9] M. Amaral, F.J. Oliveira, M. Belmonte, A.J.S. Fernandes, F.M. Costa, R.F. Silva, Surf. Eng. 19 (6) (2003) 410.

[10] I.M. Hutchings, Tribology - Friction and Wear of Engineering Materials, Ed. Butterworth-Heinmann, UK, 2003.

[11] H.D. Espinosa, B. Peng, B.C. Prorok, N. Moldovan, O. Auciello, J.A. Carlisle, D.M. Gruen, D.C. Mancini, J. Appl. Phys. 94 (9) (2003) 6076.

[12] A.C. Ferrari, J. Robertson, Phys. Rev .B 63 (2001) 121405.

[13] R. Pfeiffer, H. Kuzmany, N. Salk, B. Gunter, Appl. Phys. Lett. 82 (2003) 4149.

[14] C.S. Abreu, M.S. Amaral, F.J. Oliveira, A. Tallaire, F. Bénédic, O. Syll, G. Cicala, J.R. Gomes, R.F. Silva, Surf. Coat. Technol., in press. 